\title{
Un ECG typique d'épanchement péricardique abondant
}

\section{A typical ECG of abundant pericardial effusion}

\section{E. Lotz}

Reçu le 3 janvier 2012 ; accepté le 11 février 2012

(C) SFMU et Springer-Verlag France 2012

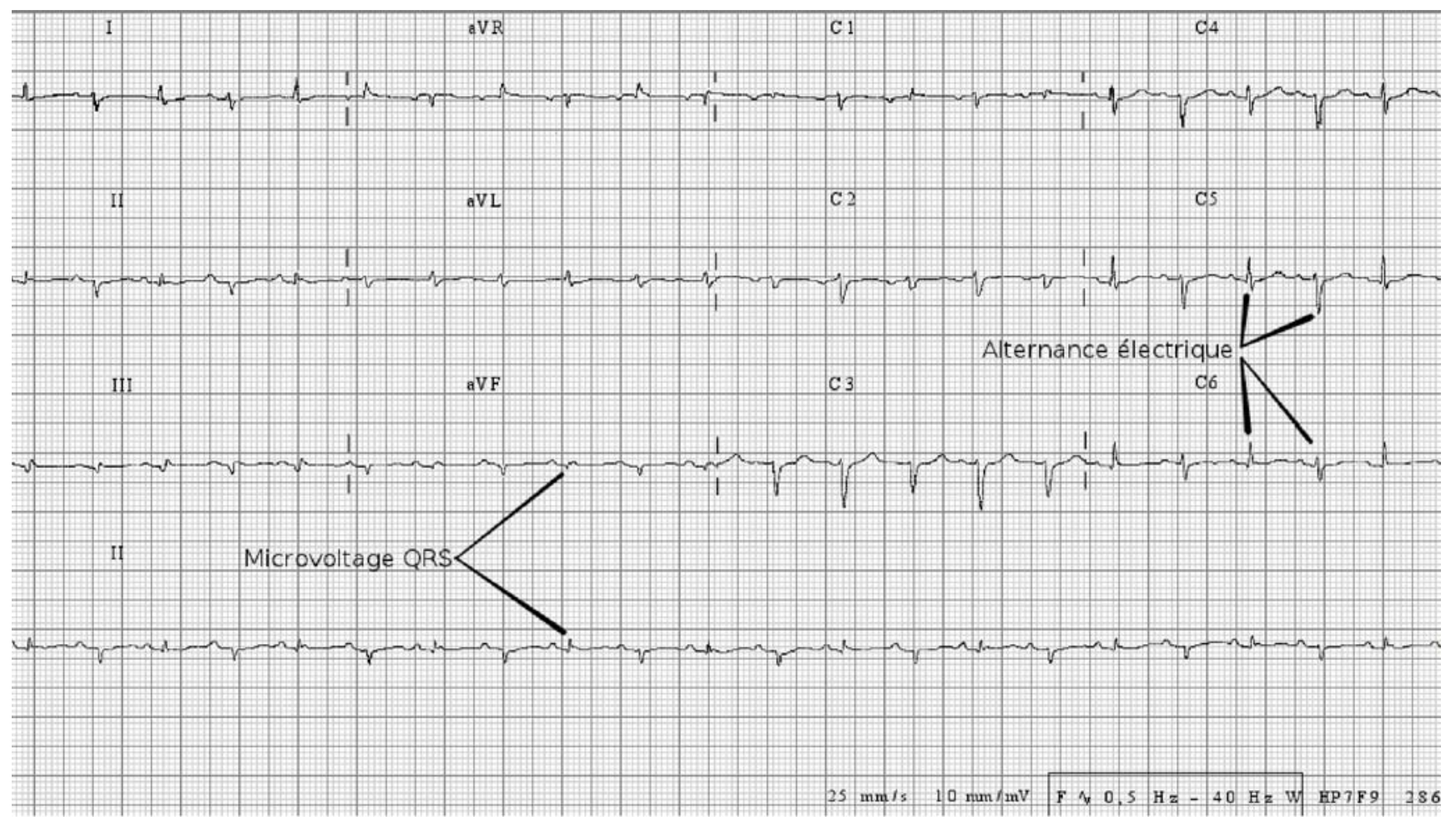

Fig. 1 Épanchement péricardique abondant avec micovoltage et alternance électrique

Voici l'ECG d'une patiente de 51 ans présentant un épanchement péricardique abondant (Fig. 1). On y retrouve un microvoltage du QRS et surtout une alternance électrique (variation périodique de l'amplitude et/ou de la morphologie du QRS un battement sur deux ou trois). L'alternance électrique peut-être expliquée par les mouvements pendulaires du cœur dans un sac péricardique rempli de liquide, mais aussi par les variations battement par battement du remplissage des ventricules. Ce signe est fortement évocateur de

\section{E. Lotz $(\bowtie)$}

Service des urgences, Hôpital Saint-Joseph,

185, rue Raymond Losserand, F-75014 Paris, France

e-mail : lotzeric@gmail.com tamponnade mais peut être également rencontré dans les péricardites constrictives, les pneumothorax sous tension, l'infarctus du myocarde avec dysfonction ventriculaire gauche sévère [1].

\section{Référence}

1. Nicolas-Robin A, Langeron O (2004) Tamponnade cardiaque. In Urgences médico-chirurgicales de l'adulte. Carli, Riou et coll. 2ème édition, Arnette Editeur, Paris, p 230-237 